Cornell Law Library

Scholarship@Cornell Law: A Digital Repository

Cornell Law Faculty Publications

Faculty Scholarship

Fall 1992

\title{
The Argument from Ordinary Meaning in Statutory Interpretation
}

Robert S. Summers

Cornell Law School, rss25@cornell.edu

Geoffrey Marshall

University of Oxford

Follow this and additional works at: http://scholarship.law.cornell.edu/facpub

Part of the Legal History, Theory and Process Commons, and the Legislation Commons

\section{Recommended Citation}

Summers, Robert S. and Marshall, Geoffrey, "The Argument from Ordinary Meaning in Statutory Interpretation" (1992). Cornell Law Faculty Publications. Paper 1207.

http://scholarship.law.cornell.edu/facpub/1207

This Article is brought to you for free and open access by the Faculty Scholarship at Scholarship@Cornell Law: A Digital Repository. It has been accepted for inclusion in Cornell Law Faculty Publications by an authorized administrator of Scholarship@Cornell Law: A Digital Repository. For more information, please contact jmp8@cornell.edu. 


\section{THE ARGUMENT FROM ORDINARY MEANING IN STATUTORY IINTERPRETATION*}

\section{INTRODUCTION}

The subject of statutory interpretation is as old as written law, yet it is by no means fully understood. The subject is also one in which legal theory and legal practice intersect at many points. One branch of the subject takes the form of an inventory and analysis of the nature and limits of leading types of interpretive arguments. This is the branch we will explore now. But within that branch, we will concentrate on only one leading type of argument in the field, namely, the argument from ordinary meaning. This has for a long while been the leading type of interpretive argument in Britain, ' and there are recent signs in the United States, especially in the Supreme Court, ${ }^{2}$ that the argument from ordinary meaning is now coming more into favour.

British judges generally deploy the argument from ordinary meaning rather well. But if that be so, then what is the problem? If the argument from ordinary meaning is essentially alive and well in the United Kingdom, then why go on about it? There are several answers. First, it is possible to perform a practice well without being able to provide an adequate second-order account of that practice. For example, it is familiar that a person may be able to give good directions on how to get around in a town, but not be able to draw a map of it. ${ }^{3}$ We believe something like this is true of statutory interpretation, and especially of the argument from ordinary meaning. Many judges, practitioners and even academics are good at the argument, yet are not notably articulate when it comes to expounding its nature, force and limits. Academics of all people should be content with achieving understanding here for its own sake. But in practical affairs, too, it is not

* IThis is a revised version of the MacDermott Lecture, delivered on 6 May 1992 at The Queen's University of Belfast by Professor Robert S Summers. Parts of earlier versions of this lecture were read at the University of Cambridge at the Jurisprudence Discussion Club on 28 January 1992, and at a Faculty Seminar at the University of Southampton on 12 February 1992. The authors - and the Editor — wish to thank the Goodhart secretary. Mrs Carol Dowling. for preparing the manuscript with efficiency and dispatch - Editor.]

1. As Lord Blackburn put it, judges should give "the words their ordinary signification": River Wear Commissioners v Adamson (1877) 2 App Cas 742. For a general account of interpretive practices in the United Kingdom, see MacCormick and Summers (eds). Interpreting Statutes - A Comparanive Study (1991). Ch 10.

2. See eg. John Doe Agency v John Doe Corp 1 I0 S Ct 471. 476 (1989): Commissirmer v Asphalt Products Co 482 US 117. 120 (1987); United States v Locke 471 US 84. 93 (1985): Griffen v Oceanic Contractors Im. 458 US 564. 570 (1982). For a general account of interpretive practices in the US Supreme Court. see MacCormick and Summers (eds). Interpreting Statutes - A Comparative Study (1991). Ch 11.

3. See Ryle. The Concept of Mind ( 1949), p 49: "Excellence at surgcry is not the same thing as knowledge of medical science." 
merely important to be good at deploying an argument; it is also important to be able to give a satisfactory account of what is involved. Even if judges and practitioners often get an argument right, it does not follow that they always get it right. And even if they always get it right, it does not follow that they always deploy it efficiently. Map in hand, they might find their way better.

There is a further reason to try to deepen our understanding of the argument from ordinary meaning. Judges, practitioners, and academics in the United Kingdom have been hearing recommendations ${ }^{4}$ from Europe and the European Community, ${ }^{5}$ and earlier on from the United States, that they would do well to abandon the argument from ordinary meaning, and instead take up in its place, as the primary mode of interpretive argument, what Europeans call "teleological interpretation" 6 and what some academics in the United States call "purposive interpretation" or what we will here call the argument from ultimate statutory purpose. ${ }^{7}$ We think it fortunate that these recommendations have so far not been adopted. Our view is that judges in the United Kingdom should generally keep on doing what they have been doing, namely, interpreting statutes where possible primarily in accord with their ordinary meaning. (We therefore also applaud the recent trend in this direction in the Supreme Court of the United States.) But to see precisely why judges and lawyers should keep on doing what they have been doing. rather than go in for teleology and purpose. we need a better understanding of the argument from ordinary meaning, of how it differs from the argument from ultimate purpose, and of why it rather than the argument from ultimate purpose should have primacy.

We will proceed as follows. In the first part of this essay, we seek to advance understanding of the argument from ordinary meaning by rebutting several forms of scepticism about it. This exercise in rebuttal comprises the major part of the essay, and it will be seen that we have no new discoveries of fact or results of legal research to reveal here. Instead, we will for the most part merely assemble reminders of the familiar and suggest an approach for organizing a coherent general view. In the middle part of the essay, we take up and rebut contentions of those who advocate the primacy of teleological and ultimate purpose argumentation. In the final part, we return to the foundations of the argument from ordinary meaning and show that it is an autonomous type of argument, the force of which is not derived from any concurrently applicable argument from ultimate purpose.

4. Some of these recommendations are referred to in the Report of the Law Commission and the Scottish Law Commission. The Interpretation of Statutes (HC 256. 1969).

5. See. for example. $R \vee R e g i s t r a r$ General. The Times, 18 November 1990 where Lord Justice Staughton wrote that a given interpretation "was consistent with the growing tendency. perhaps encouraged by Europe. lowards a purposive construction of statutes, at all events if they did not deal with penal or revenue matters".

6. See eg Kutscher. Methods of Interpretation as Seen by a Judge at the Court of Justice (1976). pp 39-41.

7. For what is probably the most influential American formulation of purposive argumentation. see Hart and Sacks. The Legal Process: Basic Problems in the Making and Application of Law (unpublished tcaching materials. 1958). pp 1148-1158 and 1410-1417. 
SCEPTICISM ABOUT THE ARGUMENT FROM ORDINARY MEANING

\section{A. Preliminary clarifications}

The argument from ordinary meaning may be defined as the argument from that meaning which a competent, knowledgeable, purposeful and informed user of ordinary language would give to the ordinary words of the statute in issue on the basis of what we will call the resources of ordinary language argumentation. Thus, the argument from ordinary meaning is not equivalent to whatever argument happens to support an ordinary meaning as the interpretation of the statute. Other leading types of argument may support an ordinary meaning as the appropriate statutory meaning, yet not qualify as arguments from ordinary meaning because they do not essentially invoke the resources of ordinary language argumentation. For example, the argument from ultimate purpose or the argument from that meaning which best harmonizes with other sections of the statute may happen to support an ordinary meaning in a particular case, yet these arguments do not appeal essentially to the resources of ordinary language.

We also differentiate ordinary meaning from literal meaning. In discussing the interpretation of laws, Blackstone mentions a case put by Cicero. ${ }^{8}$ A "salvage" law prescribed that those who in a storm forsook a ship should forfeit all property in it and the ship should belong entirely to those who "stayed" with it. One such passenger, who was by reason of illness unable to escape with the rest, claimed the ship after it by chance came safely to port. Literal usage might suggest that the sick passenger in a literal sense "stayed" with the ship and that he might claim the benefit of the law. But it is doubtful whether a competent and purposive user of the English language, knowing the facts of the case, would feel compelled to say that the sick man was someone who had "stayed" with the ship. Such a person would almost certainly understand from the words that any reward for salvage should go only to a person who by choice stayed with the ship. After all, the reward is a reward for salvage. A sick person who is unable to do anything other than remain on board is not deserving of a reward, and could not save the ship or its contents anyway. Thus, in this context, the ordinary or common usage of "stayed" - stayed by choice - can be seen to differ from the literal meaning - stayed in the sense merely of remaining on board. ${ }^{9}$ The literal sense is not necessarily a narrower meaning. In fact the literal sense in this instance embraces a wider class of persons than the ordinary sense that the informed, competent, and purposive user of English would, without more, take the word to mean.

The "ordinary" meaning should also be differentiated from the "plain" or "clear" meaning, as these terms are often used by judges and others. The

8. $1 \mathrm{Comm} 62$.

9. We might also notice that the literal use does not necessarily in a linguistic sense entail a narrower usage. 
plain or clear meaning of words is not itself a general type of meaning, as is the ordinary meaning, but rather a judgment that a particular meaning is plainly or clearly correct. Of course, in a given instance, the "plain" or "clear" meaning of the words could also be a particular ordinary meaning. But the plain or clear meaning could equally be a technical meaning, or a special meaning, rather than an ordinary meaning. Blackstone also mentions a case in which a law of Edward III forbade all ecclesiastical persons to purchase "provisions" at Rome, which he suggests might, in its ordinary meaning, seem to prohibit the buying of grain or victuals. ${ }^{10}$ But in fact the statute was made to repress the specific practice of purchasing "papal nominations" to benefices which were called "provisions" and the restraint was laid on such provisions only. For this reason, the plain or clear meaning of "provisions" was a technical or special meaning and not its ordinary meaning.

Thus we further distinguish between the ordinary meanings as opposed to technical meanings, legal or non-legal, that the statutory words might have. Ordinary words always have one or more possible ordinary meanings. Technical words always have one or more possible technical meanings. Of course, an ordinary word may have a technical as well as one or more ordinary meanings.

So, too, ordinary meanings differ from special meanings. By a special meaning, we mean either (1) a meaning different from an ordinary meaning of an ordinary word, which is not yet an established technical meaning of that ordinary word, or (2) a meaning of a technical word that is not the technical meaning of that technical word.

\section{B. Scepticism about the determinacy of the argument from ordinary meaning}

It is sometimes said or assumed that although the argument from ordinary meaning often appears on the surface to be available under a statute, on the kind of close analysis for which lawyers are well known, one or more sources of doubt will almost always emerge, thereby rendering the argument incorrigibly indeterminate for the particular case. These sources of doubt are by no means confined to adversarial contrary-mindedness. They also include ambiguity (both semantic and syntactical), vagueness, ellipsis, obsolescence, evaluative openness and more. At this point, the sceptic goes on to say that in the face of these sources of doubt, we must, if we are honest with ourselves, turn to other types of arguments such as the argument from ultimate purpose or the argument from the meaning which best harmonizes with the rest of the statutory scheme. Thus, as the sceptic sees it, such doubts simply cannot be settled by resort to the resources of ordinary language argumentation.

10. I Comm 6I. 
Now, how are we to respond to this? First, let us remember that, in a great many situations to which statutes using ordinary language apply, no really credible doubts arise, even on the surface. This is not difficult to explain. Ordinary language works rather effectively in ordinary non-legal affairs. Why should matters be different in the law?

But let us concede for the moment that various sources of doubt are in fact often at work, at least on the surface. We still contend that such doubts can usually be settled or cleared up solely by resort to the resources of ordinary language argumentation - the resources of our competent, purposeful and informed user of the language. As Aristotle so often said, we should just "look and see". If we do, we will be reminded of familiar facts facts largely of language as used in everyday life and in law.

We will now look at several simple examples, all of which are based on (though not entirely identical with) some actual cases. These examples illustrate a wide variety of sources of doubt at work; but more important for our purposes, they also illustrate how resources of ordinary language argumentation can be readily deployed to settle or clear up such doubts. Each of the examples reminds the sceptic of much that should already be entirely familiar. We have deliberately selected very simple examples, but the analysis applies to much more complex ones as well. Ultimately, what is needed here is a wide-ranging and systematic study of many examples, but that must await another day.

(1) One perhaps all too common source of doubt derives more or less solely from what we call adversarial contrary-mindedness. Suppose Parliament adopted the British Army Act, applicable to British soldiers everywhere, and it is duly promulgated in Hong Kong. Assume the Act said: "Any British soldier who commits an assault on or after I January 1957 shall be punished by court martial". Assume the defendant was convicted for committing an assault in Hong Kong at or about 2.30 am on 1 January 1957 , Hong Kong time, and he appealed, arguing that the assault actually took place the day before at $6.30 \mathrm{pm}$ on 31 December 1956, Greenwich Mean Time, and therefore, on his argument, before the statute could be in force in Hong Kong. In the case that arose, ${ }^{11}$ the appeal was dismissed, despite this argument. Indeed, counsel for the Crown was not even asked to respond to appellant's so-called "argument", presumably given the quite evident determinacy of the argument from ordinary meaning.

(2) Now, consider doubt arising from syntactical ambiguity. Suppose a statute said: "Public schools or hospitals or other public institutions for education or health care must be duly certified by the Public Health Officer as satisfying Regulations 27-30". Assume the Health Officer demanded to review and certify defendant, a private hospital. Here, we could expect the court to clear up the surface ambiguity by concluding that the statute only applies to public hospitals, since the word "public" appears initially before the phrase "schools or hospitals" and the extension of the qualifying word

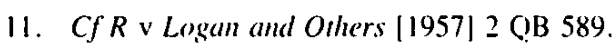


"public" to hospitals is confirmed by the word "other" in the subsequent "other public institutions" clause. Here, too, it is familiar that such surface doubt can be and often is cleared up solely by reference to the resources of ordinary langliage. ${ }^{12}$

(3) Another kind of doubt arises from vagueness. Suppose a statute provided: "Any person who is driving a motor car must have a licence". The defendant, who had no licence, was moving a car with his shoulder along a street, with one hand on the steering wheel to control its movement. Assume the court decided he could not be guilty of "driving" a motor car. ${ }^{13}$ The court reasoned that there is a firm distinction in ordinary language between driving and pushing. Without more, driving does not include pushing. If it did, even a person pushing a motorcycle along the road with no intention of driving it would be guilty, which could not have been meant. Again, the resources of ordinary language are often adequate to clear up surface vagueness in this way.

(4) Then there is the kind of doubt that arises from the high abstractness or generality of words from ordinary language, as applied to very particular circumstances. Assume a statute provided: "All mining machinery and apparatus shall be kept in a safe condition". The plaintiff was injured when a rung on a ladder broke and was not repaired. The court decided the ladder was mining "apparatus" within the statute, and appealed directly to ordinary usage as set forth in a standard dictionary which provided that an apparatus is "an assemblage of appliances or materials for a particular use". ${ }^{14}$ Here, too, though we may have wished for somewhat more, the doubt is cleared up by resort to the resources of ordinary language.

(5) A further common source of doubt is that arising from the extreme unsoundness in policy terms of the result that would follow from applying the prima facie ordinary meaning of a general term or phrase. Assume a statute directed health officers in very general and unqualified terms as follows: "The health officer in charge of birth certificates shall, on application, issue a certificate to an applicant". Petitioner, who was in prison for a two-year term, sought a birth certificate. Petitioner had, as a child, been adopted with a name change. The evidence was that Petitioner had come to loathe the idea of having been farmed out by his natural mother for adoption. Petitioner was a violent person, having committed one homicide already. Petitioner sought his birth certificate in order to determine who his true mother was. The evidence indicated that he might, after learning the identity of his natural mother, do her harm when released from prison. The court decided that the health officer was not required to issue the petitioner a birth certificate. ${ }^{15}$ Now, this result. too, can be reconciled with ordinary language argumentation. Here, we could say, as the court itself implied, that the legislature took it for granted that a health officer need not supply

12. There are countless examples of syntactical ambiguity in the reported cases - see generally. Bemnion on Statute Law (3rd ed 1990). pp 258-259.

13. $C f R$ v MacDonagh. The Times. 20 February 1974.

14. Cf Brehner v British Coal, The Times, 23 July 1988.

15. Cf $R$ v Registrar General. The Times, 12 November 1990. 
information to facilitate commission of a serious crime. In the use of ordinary language in ordinary daily life, much is taken for granted. Among other things, this requires that we read into over-general language the qualifications required by context, and we regularly do so. ${ }^{16}$ So may courts.

Of course, it is not true that in every case in which doubt arises as to the meaning of ordinary language in a statute, the resources of ordinary language can be drawn on to a substantial degree to clear up the indeterminacy. Sometimes this mode of argumentation fails, and other types of arguments must be invoked. Or sometimes this argumentation succeeds in settling the matter only with some aid from other types of arguments. For example, many vagueness cases are ones in which the prima facie indeterminacy is cleared up partly by ordinary meaning argumentation and partly by appeal to another type of argument. Consider a case in which the statute said that a seller of food must not "use tobacco while selling food" and the defendant was convicted of selling tomatoes with a cigarette that had gone out in his mouth. In that case, the court concluded both that in ordinary language the defendant could still be said, with some force, to be using tobacco, and also that such an interpretation would implement the ultimate purpose of the health regulation, because even cold ashes falling on the tomatoes would be unhealthy. ${ }^{17}$

We have now identified a number of familiar sources of doubt that motivate sceptics to claim that the argument from ordinary meaning is by nature incorrigibly indeterminate. Yet in each of the foregoing examples we are reminded of how familiar resources of ordinary language argumentation can be drawn upon by the courts to clear up such doubts. Ultimately, much more scholarship is required here. A more detailed and wide-ranging study of examples, complex as well as simple, must be conducted so that we can classify, analyse, systematise, and determine the appropriate role of particular types of resources of ordinary language argumentation.

In addition, when judging the overall determinacy of the argument from ordinary meaning, we must consider not only the trouble cases reaching the courts under a statute, but also the many more cases that never reach the courts because the ordinary meaning of the statute is sufficiently determinate. The sceptic tends to feed off the borderline and other trouble cases that do pose difficulties for courts. Again the sceptic must be reminded that in daily life ordinary language generally works pretty well. Why should it not work similarly well when harnessed to legislative ends?

But scepticism about the determinacy of ordinary language argumentation does not stem solely from the wide range of sources of doubt that frequently give rise at least to prima facie or surface statutory indeterminacy. Often the sceptic also assumes or asserts that even in cases where the indeterminacy is said to be settled or cleared up, this resolution is

16. See generally MacCallum, "Legislative Intent" in Summers (ed), Essays in Legal Philosophy (1970), pp 254-260.

17. Cf Pitt v Locke (1960) 125 JP 93. 
arbitrary and thus dependent solely on ad hoc agreement rather than on anything that can be called a general argument from ordinary meaning. Here the sceptic will stress that we do not have an accepted general procedure or methodology for settling doubts in the name of ordinary language argumentation.

In this essay, we can only indicate suggestively how one might respond to this turn in the sceptic's position. We will begin with an explanation of what we generally mean by a competent user of ordinary language. We do not say that ordinary meaning is the meaning that the common or average or popular user of the language would give the statutory words in the general context of their use. The common or popular language user in any language is likely to use words loosely and incorrectly. Do we then mean "the standard user" in the sense given to that term in phrases such as "standard English"? But there are notoriously many levels and standards of linguistic competence even within a single community. What kind of competence would such a standard user have? Perhaps at a minimum this person would have to know how to use a dictionary and to be familiar with the rules of grammar, syntax and punctuation (but how competent and how familiar?). Certainly if a possible meaning of the statutory word can be found in a standard dictionary, this will be a step.

And, dictionary in hand, the general context to which the statute is addressed may rule out several of the alternative meanings listed in the dictionary for a given word. For example, the word "draw" will be listed with several meanings, and it will mean something in a statute regulating the use of water that is different from what it will mean in a statute regulating the use of bills of exchange.

Another general determinant will often be whether and how far a given dictionary meaning coheres with the apparent ordinary meanings of other words in the statutory phrase, or sentence, considered as a discrete linguistic unit recognized in the grammar and syntax of ordinary language.

We are mindful that "knowing how to use a dictionary" is not an unproblematic idea, though very little has been written about it in the context of statutory interpretation. It means more than knowing how to find a particular word and how to understand what the dictionary entry contains. Dictionaries do not come near to teaching anyone how to use words. What they provide is a list of possible meanings of words, including collections of synonyms and near synonyms. They also often contain illustrations of usage. A newly arrived Martian who was provided with the twenty volumes of the Oxford English Dictionary and with as many works of English grammar and syntax as he wanted would not find himself knowing how to use a dictionary, still less knowing how to use the English language correctly and appropriately.

Our competent user of ordinary language is, of course, also a purposive user, but in a qualified way. Every statute has implementive language and the implementive language of nearly every statute is expressed to a 
significant degree in ordinary language. This is necessarily a purposive use of ordinary language, and unless the legislature indicates otherwise, we are to assume that one of the purposes of the legislature is that ordinary words in the implementive language are to be given their appropriate ordinary meanings. This purpose may be characterised as the legislature's immediate purpose in using implementive language, and our notional competent language user takes on this purpose. To cite an example, the immediate purpose of the legislature in that most famous of all statutes, "No vehicles in the park", is to use the device of a regulatory statute to keep vehicles, in the ordinary sense, out of the park. Accordingly, our notional competent user of language, interpreting the statute partly in light of its immediate purpose, will, without more, attribute the appropriate ordinary meaning to the word "vehicle". Of course, the legislature will also have one or more ultimate purposes in enacting the statute, too, including perhaps the reduction of noise, the promotion of safety, the preservation of clean air in the park, etc. But as we will see, such ultimate purposes will often prove problematic when deployed in interpretive argument.

Thus, ordinary meaning argumentation is not purposeless. It has regard at least to the immediate purpose of the legislature in using ordinary language in the implementive provisions of the statute. It will therefore usually help to ask: what meaning would a competent and purposive user of these ordinary words in such circurnstances mean to convey?

So in identifying the standard user of the language for purposes of explicating ordinary meaning argumentation, it seems that we must be referring not just to a common or popular talker but to a putative or notional figure who is a competent and purposive user of the language. This person will usually have grown up using the language, will have undergone various kinds of experiences and acquired certain kinds of knowledge. But then, we may wonder, how much knowledge and what kinds of knowledge? What general knowledge? If we consider the language of modern statutes it is possible that some of them may be understood and made sense of by a language user who knows little or nothing about, say, psychology, economics, geography, or business. But nowadays there are fewer and fewer statutes of which that would be true. So our notional ordinary language user has to be an educated user with a background of general knowledge who is capable of understanding terms of some complexity. This user must know at least the "basics" of many subjects.

Our notional figure must also be someone who can cope with conceptual complexity. Even many simple-sounding and quite ordinary words have complex ordinary meanings, ie, complex conceptual content. This is true of even elementary sounding notions of individual responsibility. Consider "dishonest" or "reckless", for example.

Often it is necessary to decide whether ordinary words apply or are appropriately used in circumstances that may not previously have occurred even to a competent, purposive and knowledgeable language user. This requires the ability to consider hypothetical arguments, to compare the force 
of rival analogies, and to deploy abstract reasoning of a not very ordinary order. But to do these things is not to leave the world of ordinary language and enter a specialized legal world governed entirely by some special tongue. Conclusions reached here about meaning can usually be reached in the name of ordinary language argumentation.

Many cases involving statutory interpretation turn on the application of a general term in a statute to novel factual situations. Is milk a "beverage"? ${ }^{18}$ Is blackcurrant syrup a "medicine"" 19 Is nude male bathing in the presence of ladies "indecent"? ${ }^{20}$ Is disrupting a tennis match "insulting behaviour"? ${ }^{21}$ Is a person pushing a car and using the steering wheel "driving"?

These words are all ordinary words in the English language avowedly used not in any technical or special senses, but in their ordinary senses or meanings. Now what does it mean to say that the questions posed about the uses in the cases in question can be answered by our notional language user who appeals to what we call ordinary language argumentation? Certainly we do not say that ordinary language always dictates an answer. What then is the point of saying that we are applying our understanding of the ordinary meaning of words to such questions? There is perhaps the obvious contrast with the idea of applying words in some secondary or clearly different technical or special sense. Resolving cases such as those in the examples we have given is not at all like taking some naturally or obviously occurring prima facie ordinary sense and modifying it in the light of various kinds of knowledge or expertise. The knowledge or expertise is what fixes or goes to fixing or drawing out the ordinary non-technical and non-special usage that the language has. For example, in one type of case, we do not take a term such as "driving" in the statute against driving without a licence and modify it in light of our knowledge of the language. Rather we settle the ordinary meaning in this set of circumstances in light of, for instance, our knowledge that the language has a much more apt word, namely "pushing", to cover the facts of the case that has arisen (pushing a car without a licence to drive), and therefore we decide, in the absence of anything further, that "driving" does not apply. In this way we are operating with the language, not on it. To operate with language in problematic situations requires us to bring to bear understanding of the language, general knowledge, awareness of the immediate purpose of the legislature, hypothetical case analysis and reflective capacity. As Glanville Williams has said:

"We understand the meaning of words from their context, and in ordinary life the context includes not only the other words used at the same time but the whole human or social situation in which the words are used."23

Now we must fill out the idea of ordinary meaning in ordinary language to include the meaning that would be attached to words not only by the

18. $R$ v Rouse [1936] 4 DLR 797.

19. Customs and Excise Commissioners v Beecham Foods Lid, The Times, 26 January 1972.

20. $R \vee$ Stanley [1965] 2 QB 327.

21. Brutus v Cozens [1971] 2 All ER 1297.

22. $R$ v MacDonough [1974] 2 All ER 257.

23. "The Meaning of Literal Interpretation" (1981) 13I New LJ 1128, 1129. 
competent, generally knowledgeable, purposive and reflective user, but also by the specially informed and instructed user of the language for the particular circumstances in question. Suppose a statute limits the amount of contributions to electoral expenditures by persons who "promote or favour the election of a candidate". Does a person who campaigns against a candidate at an election "promote or favour the election of a candidate"? On the face of it the phrase "opposing a candidate's election" does not mean "promoting a candidate's election" and someone who had done the first might say that he had not in the ordinary sense of the words done the second. Nonetheless, a competent, generally knowledgeable and specially informed ordinary language user who was familiar with or had the factual background of elections and electoral machinery drawn to his attention might come to agree that his doing of the one act was equivalent to his doing of the other, given the language and the immediate purpose of the statute evident on its face and inferable from the ordinary meaning of the language used. ${ }^{24}$

In many problematic cases no special factual instruction is necessary but the language user may need to be reminded of, or have suggested to him, factual considerations or distinctions that might not occur naturally. Consider the argument reported in a typical case of this kind. In Newbury v Cohens (Smoked Salmon) Ltd ${ }^{25}$ the issue was whether a Sunday trading ban which permitted the sale on Sunday of only certain categories of articles, including "meals or refreshments", permitted the sale of raw kippers and packets of tea. It was argued for the prosecutor that kippers in a raw or uncooked state were not within the meaning of "meals or refreshments" since the bulk of people or reasonable people did not eat raw kippers or tea. Various considerations were advanced, including the following:

The Lord Chief Justice: Why is it so extraordinary that people eat kippers without cooking? We do not know what the inhabitants of Clapham like. Counsel submitted that "meals or refreshments" meant such things as a bun or a snack, such as might be got in a railway refreshment room.

Mr Justice Cassels: One cannot allow a railway refreshment room to be a standard when one reflects what cannot be got there.

The Lord Chief Justice: I do not think anyone eats a leg of mutton raw.

Mr Justice Cassels: There is a school of dieticians which advocates eating raw food. There is a common that some gentlemen are eating their way across.

Mr Justice Donovan: Does "meals or refreshments" mean for human beings only? Why shouldn't raw' kipper be a meal for my cat? (Counsel for the shopkeeper submitted that the words were wide enough to include all food, cooked and uncooked, consumed by human beings.)

The Lord Chief Justice: That is the difficulty. You do not consume tea but water in which the tea has been infused together with cream, milk or lemon. But it might not mean that you could not buy cocoa on Sundays

24. DPP v Luft [1977] AC 962 (pamphlets urging "Don't vote National Front").

25. The Times, 27 April 1956. 
because cocoa is consumed. Children eat it out of the tin. Everybody knows that and they get smacked for it.

The Lord Chief Justice, giving judgment, said that you could sell smoked salmon, you could sell smoked trout, smoked eel or other varieties of herring and yet it was said that you could not sell smoked herring, namely a kipper. In his opinion it was impossible to say that a kipper could not be a "meal or refreshment". It could be a very good meal. But he felt some difficulty about the packet of tea.

In this case the special facts and circumstances appealed to - eating habits; routine culinary experience; the character of railway refreshment rooms; the behaviour of children - seem to be things already within the experience of the ordinary knowledgeable language user, including, of course, the experience of the statutory drafter and statutory interpreter, and their bearing on the issue in hand involves, perhaps, not only special factual instruction, but also reminding, reflecting, weighing and assessing the known facts in various hypothetical lights.

The types of general resources of ordinary language argumentation that we have identified here, and the suggestions we have made as to their general deployment, do not yet rise to the level of a general procedure, let alone one publicly acknowledged among lawyers. But we believe this account should at least fend off the most radical indeterminacy sceptics who assume that in cases of dispute, there is no general way to determine ordinary meaning at all. The various resources to be brought to bear by the ordinary language user include: general linguistic competence, dictionaries, grammar books, the bearing of a general context of usage, general knowledge of the language user, purposive analysis drawing at least on immediate purposes in the circumstances, the drafter's knowledge of usage in parallel circumstances in ordinary life, special factual knowledge, reminders of factual considerations already familiar, the use of hypothetical analysis, analogy, standards of consistency and systematic reflection.

The ordinariness of ordinary language when thus brought to bear is not easy to describe in general terms. What we are concerned with seem to be conclusions as to the meaning of ordinary words that are drawn or coaxed out of the use of words by our competent, purposive and knowledgeable language user after due reflection and possible argument. In this sense we may claim that ordinary language may contain a solution to an interpretive problem though it will not necessarily dictate it or bear the solution on its face.

A great many problems of statutory interpretation, then, will go away because ordinary language can be made sufficiently determinate for resolution of the case at hand. But, as we have said, a comprehensive and systematic study of a wide range of examples, complex as well as simple, is needed here, and would cast much light both on the nature and variety of the resources of ordinary language argumentation and on just how it settles doubts. In the end we might even reconceptualize and retitle our subject not as "the argument from ordinary meaning" but as a variety of 
language-oriented arguments for refining meaning or settling doubts about ordinary words.

Even when the process of ordinary meaning argumentation yields a determinate conclusion, the interpreter should consider other types of argument as well. Further analysis may yield an argument that lends additional support to the argument from ordinary meaning. Indeed, in those cases where ultimate purpose can be satisfactorily shown, it is entirely expectable that ordinary meaning will be found to serve some ultimate purpose, too. But a conflict may arise between ordinary meaning and some version of an ultimate purpose argument, too (or between an ordinary meaning argument and still another type of argument). On this, more later.

\section{Scepticism about whether the argument serves interpretive values and thus has justificatory force}

We now turn away from indeterminacy scepticism to scepticism about whether the argument from ordinary' meaning serves interpretive values and thus has genuine justificatory force. The sceptical position here is frequently that the use of language in a statute is such a specialized use that an ordinary meaning of any ordinary words appearing therein can have no essential relevance to statutory interpretation, and therefore no essential relevance to the values to be served by genuine interpretive argument. On one radical version of this sceptical view, the specialized statutory use of words is a special "socially instrumentalist" use. Thus, statutes exist not to communicate meaning in a fashion that is generally the same as, or analogous to, the way competent, knowledgeable, purposive and specially informed users of ordinary language communicate meaning. Rather, statutes exist as social instruments to advance public policies, vindicate authoritative moral precepts, uphold social norms and the like. These socially instrumentalist uses of words are not really analogous to, let alone the same as, ordinary uses of language. Law is first and foremost "policy", whereas ordinary usage is merely "linguistic", and the merely linguistic is not itself policy oriented. Accordingly, the language of the law is almost always heavily freighted with special or technical meanings, not ordinary meanings. It follows, or so it is said, that ordinary meanings cannot, as such, serve statutory ends, and therefore cannot serve any genuine interpretive values.

In our view, this radical form of scepticism does not call for extended rebuttal. The language of most statutes, however "socially instrumental", consists overwhelmingly of ordinary words used by drafters who, we may assume, are competent, informed and purposive users of ordinary language addressing audiences of competent, informed and purposive users of ordinary language. Thus, when a statutory drafter uses ordinary words, we may assume that those words are being used with appropriate ordinary meanings unless a technical or special meaning is shown. And even when statutes are drafted with technical or special meanings, this will almost 
always be in the syntax and grammar of ordinary language, and many ordinary words with ordinary meanings will frequently appear.

Moreover, ordinary meaning can be readily harnessed to many socially instrumental ends. We do not require two languages, a "socially instrumental" language for use in statutes, and ordinary language. Nor is it difficult to explain why this is not necessary. The kinds of communicative demands that drafters of statutes must meet regularly arise in daily social life where ordinary language is at work. We saw clearly how this was so in earlier examples, including the case from Blackstone in which a claimant who "stayed" with a ship in distress merely because of illness was denied the rights of a salvor. The competent, informed and purposive language user in ordinary life would not suppose "stayed" in a salvage law to include an immobile sailor who was in no sense a ship salvor.

We turn to a less radical form of scepticism here. The sceptic may concede that ordinary language is an indispensable resource for the drafter but question whether the argument from ordinary meaning can consistently or sufficiently serve interpretive values. On one view, ordinary language is thought to be too "acontextual" to do this. This kind of scepticism may be countered first by pointing to the elemental fact that legislatures, as collective bodies, can legitimately act only via some kind of formal assent to, and enactment of, words in fixed verbal form. Insofar as the statute is drafted in ordinary language, we must, without more, assume that the legislature voted on and adopted the statute understanding it in terms of the ordinary meanings of ordinary words in it. In this way, ordinary language is an essential vehicle for the expression of democratic will. In giving effect to ordinary meaning, the interpretive argument not only serves democratic will but also facilitates the accountability of legislators to the electorate. These are interpretive values of the highest order.

A further interpretive value that the argument from ordinary meaning serves is this. It is more susceptible of even-handed application across time and space in the hands of different and changing judicial and administrative personnel, and in the hands of lawyers advising clients, than is any other mode of argument (except the argument from technical meaning). This is a not inconsiderable value, given that predictability and equality before the law are at stake.

Further, the ordinary meaning of the statute serves to constrain wilful judges (of the left and of the right), thereby confining them not only within their sphere of competence but also within their appropriate judicial role. Courts lack institutional competence to make fully-fledged legislative judgments about ends and means, and ought not to substitute their judgment for that of the legislature anyway. This erodes the very phenomena of legislation and of legislative power itself.

Adherence to ordinary meaning also affords those who must rely on statutory language from the time it goes into effect rather more protection than interpretive arguments which take account of materials extrinsic to the 
statute not readily available to addressees at the time of reliance. Relatedly, adherence to ordinary meaning generates reasons for citizens to act from the effective date of the statute (which is when they have to act), rather than postponing the ascertainment of authoritative meaning to the point of application by a court (as is often so with the argument from ultimate purpose).

Finally, the argument from ordinary meaning encourages legislators to legislate consistently with the rule of law. By adhering to ordinary meaning, judges in turn encourage legislators to draft openly and carefully. They invite legislators to legislate explicitly and thus not through "legislation" hidden in mere legislative history and similar "legislation" that might well not have gained true assent if more explicit language had been used in the statutory text.

\section{Scepticism about the availability or decisiveness of the argument from ordinary meaning}

A further fundamental form of scepticism about the argument from ordinary meaning is that it is available only occasionally, or is not very decisive when available, and therefore cannot be a major justificatory resource in statutory interpretation.

First, the sceptic assumes that the conditions for the availability of the argument frequently do not exist. The conditions required for the availability of the argument from ordinary meaning consist of: (1) a section of statutory text which is itself at least partly cast in ordinary language; (2) relevant conventions of ordinary usage; (3) the various other resources of the hypothetical or notional ordinary language user who, as we have seen, must be a competent, knowledgeable, purposive and informed user of language with capacity for argument and reflection, and (4) the absence of irreconcilable ambiguity, vagueness, generality, ellipsis, obsolescence, evaluative openness, and the like. When these conditions are not present, no credible argument from ordinary meaning can be available at all. The sceptic assumes that unavailability of the argument is the rule rather than the exception, and thus that commonly the resources of ordinary language cannot clear up any prima facie indeterminacy. In turn, this general state of affairs is attributed to such factors as poor drafting, the nature and limits of language and lack of foresight.

Now, this first source of scepticism might, in principle, be assessed in light of an extremely tedious and complex factual inquiry which, needless to say, no one has ever undertaken. Indeed, to our knowledge, no one has ever tried to estimate, even in a small and discrete branch of a given field of law. the proportion of instances in which the general conditions for the ultimate availability of the argument from ordinary meaning appear to be present.

Nevertheless, it just is a fact that every year, the highest courts in the United Kingdom decide a significant number of cases in which they say that 
the argument from ordinary meaning is controlling or substantially controlling. The judiciary and practicing lawyers do not view such cases as oddities or aberrations. Even if it were true that such cases represent a relatively small proportion of the total number of disputed statutory interpretation cases in each field, it would hardly follow that the argument from ordinary meaning must only be a minor justificatory resource. That is, so long as the highest courts accord appropriate force to the argument from ordinary meaning even in the relatively few cases that do reach those courts, it is probable that the argument from ordinary meaning similarly serves as a major justificatory resource both in the many litigated cases that never reach the highest courts and in the still far greater number of disputed cases that are never litigated at all.

One should strive for comparative perspective here. Just what type of argument can count as a "major" justificatory resource? Presumably this at the very least includes a type of argument that is as often in play, and is as widely decisive, as each of the other leading types of arguments recognized in statutory interpretation. Compared to virtually all other major types of arguments recognized in the field of statutory interpretation, there are strong reasons to suppose that the conditions required for the argument from ordinary meaning to be available and to have decisive force exist at least as often, if not much more often, than is true of any one of the other leading types of argument.

The distinct argument from the technical meaning of ordinary, or of technical, words is the only serious rival of the argument from ordinary meaning in terms of frequency of availability. Without attempting any kind of quantitative study, we may confidently affirm that the argument from ordinary meaning is in play at least as often as the argument from technical meaning. Many statutes have no or very few technical words, and it is not uncommon that ordinary words in a statute have their ordinary meanings.

The independent argument from harmonization with the general statutory context might be thought a serious rival of the argument from ordinary meaning; but in its most powerful forms, the harmonization argument requires for its availability other sections of the same statute or sections of closely related statutes that are appropriately worded, and such materials frequently do not exist.

It might be thought that the argument from ultimate statutory purpose is also a close rival; but, again, this is not so. The conditions for the availability of this type of argument are frequently not present. Thus, authoritative evidence of ultimate statutory purpose may not exist. Or if it exists, it may point quite ambiguously to different and conflicting ultimate purposes (as is frequently true in American cases). Or an authoritatively formulated ultimate statutory purpose may be very general and thus fail as a decisive criterion for determining which of two or more interpretations best serves the ultimate purpose. Or the facts may not be clear as to which competing interpretation would more efficaciously serve the ultimate statutory 
purpose. Or the implementive language of the statute may not be worded in a way that truly bears the strain of a purposive argument.

Even in the American federal system, the conditions for credible arguments from subjective legislative intent (rooted in materials of legislative history such as committee reports) are not sufficiently often available for this type of argument to be a major rival of arguments from ordinary meaning. Indeed, the conflicting and indeterminate nature of the legislative history materials in the American system is notorious. In the United Kingdom, it is generally not appropriate for counsel even to put most such material before the judge. (Of course, it is true that when the argument from ordinary meaning is not available, one or the other major types of argument such as the argument from ultimate purpose may possibly be available, but this proves nothing.)

A second basic source of scepticism about the overall justificatory significance of the argument from ordinary meaning may seem more important. Even if the argument is available, it still may be:

(1) cancelled, or

(2) over-ridden under a priority rule, or

(3) outweighed.

These truths, however, do not really diminish the overall decisiveness of the argument. What is true here of the argument from ordinary meaning is true of all the other leading types of interpretive argument as well. Any of them may be cancelled or over-ridden, or outweighed. If these possibilities imply that the argument from ordinary meaning cannot be a major justificatory resource, then no interpretive argument can ever be such a resource. There is no evidence that the argument from ordinary meaning is more often cancelled, or over-ridden, or outweighed than is true of any other possibly leading type of argument.

The third basic source of scepticism about the overall justificatory significance of the argument from ordinary meaning is that this argument is not alone enough to justify the interpretive conclusion in some cases. For example, in borderline cases under a vague statute, the argument from ordinary meaning may require reinforcement from contextual harmonization or from ultimate purpose. But, again, this is true of all leading types of argument. They just are deployed in some cases in which they require reinforcement from another argument if the interpretation is to be well justified, overall. Thus, there is nothing special here about ordinary meaning argumentation.

III

WHY TELEOLOGICAL OR "ULTIMATE PURPOSE" ARGUMENTATION SHOULD
NOT TAKE PRIMACY

We now take up a second basic theme of this essay, namely, why the teleological mode of argumentation (as it is often called in the European 
Court of Justice and in the European Community generally) or the argument from ultimate statutory purpose (as it is sometimes called by its advocates in the United States) should not take primacy over the argument from ordinary meaning, at least in regard to most kinds of statutes. Not many years ago, the English Law Commission received recommendations that the ultimate purpose argument should be imported from America and become the primary mode of interpretive argumentation in the United Kingdom. ${ }^{26}$ People here were not persuaded. Today the entreaties come more from Europe. We have not yet found any significant cases in which British judges could be said plainly to have succumbed. But purposive argumentation has been mentioned in various cases. ${ }^{27}$ It has also been put forward in a House of Lords debate on interpretive method. ${ }^{28}$ Some British treatise writers may now be headed in this direction too. ${ }^{29}$

A type of argument may be said to have primacy among interpretive arguments when it is available in a significantly higher proportion of cases than any competing type of argument. The argument from ultimate purpose cannot have primacy in this sense over the argument from ordinary meaning. It is common that reliable evidence of ultimate purpose is not available to the interpreter. It is one thing to be able to read an immediate purpose off the implementive language of a statute. Thus, the immediate purpose of a statute stating "no vehicles in the park" is to use the device of enacting a regulatory statute to keep vehicles, in the appropriate ordinary sense, out of the park. But a statute in the United Kingdom (and in the United States) typically incorporates no explicit statement of ultimate purpose, and frequently, as with the "no vehicles" statute, we can imagine a whole range of possible ultimate purposes any one of which, if taken as authoritative, might yield different results in particular cases. Moreover, in the United Kingdom, counsel may not cite most major forms of legislative history as evidence of ultimate purpose. On the other hand, materials for reliable construction of an argument from ordinary meaning are commonly available.

We have already alluded to many other problems in applying the argument from ultimate purpose. Even if an authoritative ultimate purpose can be ascertained, it will often itself be very general, and so indeterminate. And even if it alone would be determinate, several ultimate purposes of the same statute will often appear, and some will conflict with each other. Further, it may not really be clear from the facts which of two possible interpretations of the implementive language would best serve even an authoritative and otherwise determinate ultimate purpose.

There is a further basic problem with the argument from ultimate purpose that limits its availability and force in a very large category of cases, a problem almost entirely ignored in the academic literature. Legislation, particularly of a regulatory or penal kind, may superficially have a single

26. See supra $\mathrm{n} 4$.

27. See eg supra $\mathbf{n} 5$.

28. See $503 H L$ Debs, cols 278 el seq ( 18 January 1989).

29. See eg Bell and Engle. Cross on Staturory Interpretation (2nd ed, 1987). p 95. 
stated or obvious objective. The purpose of road traffic regulation is to promote road safety. The object of mine safety laws is to promote safety in mines. But these are only abbreviated statements of the statutory purpose which is not to promote the stated objectives in any and every way whatsoever, but to promote them by the means and through the words set out in the statute and not to do so in any other way. It is almost as much an object of a penal statute not to convict those who do not fall within its provisions as to convict those who do. So if the issue is whether particular persons or circumstances fall inside or outside the statute's provisions, the statute's ultimate purpose will itself not resolve such an issue and appeal to it will commonly be empty or tendentious. Thus, if a legislature enacts "No firearms in the park" with the general objective of preventing danger (rather than for example prohibiting anything likely to be dangerous), a full statement of the legislature's ultimate purpose would include the propositions that it was to permit danger in the park if not arising from the presence of a firearm and also to ignore the fact that some firearms might be brought into the park without danger (yet still violate the statute). In such circumstances, an argument from ultimate purpose will not be conclusive in determining whether a catapult or a bow and arrow is a firearm (though it might have some relevance), and the argument ought not to produce the conclusion that rifles carried in a ceremonial parade (without permission) are not firearms. In sum, because of the foregoing considerations, the argument from ultimate purpose, when such purpose is faithfully and fully characterized, will frequently have little, if any, independent bearing on the appropriate scope of a general or vague statutory term.

We now turn to a second and rather different sense in which a type of argument may have primacy. Thus, an argument may be said to have primacy if, in cases of conflict with other arguments, it generally should prevail. In this sense, too, the argument from ordinary meaning has primacy over the argument from ultimate purpose. At the very least, a credible argument from ordinary meaning should prevail over a conflicting argument from ultimate purpose, unless the latter happens to be exceptionally strong. Several factors justify subordinating the argument from ultimate purpose in this way. Among other things, the argument from ultimate purpose generally does not implement democratic will and secure democratic accountability as fully as the argument from ordinary meaning. Indeed, the ultimate purpose argument may even frustrate democratic will, given that it implicitly delegates to judges discretionary power to determine what the ultimate purpose is, and to determine the implications of that ultimate purpose for construal of the implementive language of the statute. In actual operation, this mode of argumentation invites strong-willed judges, in effect, to substitute their own views for the views of the legislature, an event which has occurred in the United States twice! The argument from ordinary meaning, taken seriously, allows much less scope for this. ${ }^{30}$

30. We are not unmindful that some sceptics would argue that, on the contrary. the argument from ordinary meaning is itself often deployed by judges to implement. yet hide. their own value preferences. Here we must distinguish two versions of the sceptical position. On one version. the language of the statute really does have the ordinary meanings that the 
Furthermore, the argument from ultimate purpose generally does not serve what might be called "rule of law" values as well as the argument from ordinary meaning. Precisely because the argument from ultimate purpose at least implicitly confers discretion on judges to determine ultimate purposes and their interpretive implications, the authoritative meaning of the statute frequently cannot be known until the statute is interpreted at the point of application where such discretion has to be exercised. This means that instead of statutes constituting meaningful reasons on which citizens may act from the time of enactment, citizens must often wait to point of application by a court to determine what the law is, a process that undermines predictability and upsets the reliance of citizens on antecedent law rather more than where the argument from ordinary meaning has primacy.

In addition, the statutory draftsman has more difficulty drafting effectively where the legislation is to be interpreted primarily in accord with an ultimate purpose, than where the legislation is to be interpreted primarily in accord with ordinary meanings of words used. The drafter will frequently be without legislative authority to insert a given ultimate purpose unless it happens to be vague and indeterminate and thus unobjectionable to all legislators. It just is a fact of legislative life that legislators can far more readily agree on implementive language than on the reasons - the ultimate purposes - for adopting such language. Moreover, when legislators do agree on implementive language, that language itself almost always reflects compromises between competing ultimate purposes. In such circumstances, it is not faithful to the realities of the legislative process to seize upon one of these purposes as the basis for extending or limiting the implementive language. The argument from ordinary meaning, however, is not similarly problematic.

court attributes to it. Here, presumably the value choices of the legislanture are appropriately implemented in accord with the argument. The fact that values of the judges are also at the same time implemented, though "covertly" without the judges owning up to it, is irrelevant and can be disregarded. even though implementation of these values might well be the true motivation of the interpreting court.

The other possible version of the alleged abuse is more troublesome. We are presumably to suppose that, on appropriate analysis. the argument from ordinary meaning is not really available because the conditions of its applicability are missing. or though these conditions are present. doubt remains which the argument from ordinary meaning does not sufficiently settle. yet the court invokes the argument to further its own value choice covertly, that is. without explicit acknowledgement of that choice. Several things should be said about this. First, it will often be difficult to know whether this is really what is going on because there will be little. if any. evidence that the court is in this way seeking to vindicate its own value choices as opposed to the presumed value choices of the legislature. Secondly, just how often this occurs and the proportion of instances in which it occurs is very difficult to assess. Materials for the appropriate empirical study are not really accessible. Thirdly, we may point out that the court's unjustified invocation of the argument from ordinary meaning merely as a cover for its own value choices is, when this is publicly evident. subject to criticism by higher courts or by commentators (or both). criticism that will have some corrective effect generally, albeit not necessarily in the particular case. 


\section{IV}

\section{THE AUTONOMY OF THE ARGUMENT FROM ORDINARY MEANING}

We now turn to the ultimate trump card of the teleologists. This is the view, seldom set forth explicitly, that whenever the argument from ordinary meaning itself appears to have force, this is really attributable ultimately to a concurrently available argument from that interpretation which best serves the ultimate statutory purpose, even though that argument may not even be set forth in the opinion. ${ }^{31}$ On this view, the apparently autonomous force of the argument from ordinary meaning is in the end illusory. Rather the force of any argument from ordinary meaning is always entirely parasitic on a distinct and independently significant argument from ultimate purpose that is available on the facts, even if not set forth. According to the teleologists, when ordinary meaning does happen to serve the relevant ultimate statutory purpose, an interpretation to that effect is justified, but solely for that reason. To illustrate: Assume a statute has as its ultimate purpose to secure quiet and safety in the park, a purpose explicit in materials of legislative history. The statute adopted says: "No vehicles in the park". Here what we call the immediate purpose appears in the implementive language, namely, to use the device of enacting a statute to keep vehicles out of the park. Even though the ordinary meaning argument would obviously exclude a sports car from the park, the sceptic would here attribute the apparent force of this argument entirely to the way this ordinary meaning serves the ultimate purpose.

We now offer three brief rebuttals to this sceptical line. First, the argument from ordinary meaning will frequently be available in a case although an argument from ultimate purpose will not be available in that case, because, for example, we cannot reliably determine a single guidesome ultimate purpose. In such a case, the force of the argument from ordinary meaning simply cannot be dependent upon the concurrent availability of the argument from ultimate purpose. In fact, judges frequently invoke the argument from ordinary meaning to justify an interpretation without at the same time invoking any argument from ultimate purpose. In many such cases it is difficult to see how an argument from ultimate purpose could be available on the facts. Consider this example. A statute (also posted on a sign) says: "No vehicles in the park". A court interprets the statute to rule out the use of battery-driven wheel chairs on park sidewalks, and invokes the argument from ordinary meaning during the course of which the court cites a dictionary definition of vehicle: "a means of conveyance provided with wheels or runners and used for the carriage of persons or goods". Assume that the court does not. however, also go on to invoke the argument from ultimate purpose of the statute, for lack of reliable evidence of ultimate purpose. Assume the court adds:

"We have reviewed all the evidence and we find no satisfactory evidence of ultimate purpose here. Internal legislative history, messages of the executive.

31. For variants of this view. see Hart and Sacks. supra n 7 at $\mathrm{p} 1157$. See also Fuller. "Positivism and Fidelity to Law - A Reply to Professor Hart" (1958) 71 Harv'LRev 630. 663. 
reports of commissions, and the like are silent or quite conflicting as to ultimate purpose. Further, there is no separate ultimate purpose clause in the statute only the above implementive language ("No vehicles in the park"). Also, the implementive language does not itself express any ultimate purpose as would, for example, a statute providing "No noisy vehicles in the park", and the word "park" is itself quite ambiguous as to ultimate purpose, which could be quiet, safety, health (no exhaust fumes), aesthetic concerns, etc. In addition. no ultimate purpose is inferable from other related statutory sections, for there are none. Then, too, we cannot infer an ultimate purpose by way of contrast with the wording of prior law. The statute is entirely new. Moreover, we cannot reliably infer a single ultimate purpose by (a) constructing hypothetical instances of unquestioned application of the statute, and $(b)$ rendering explicit the ultimate purpose implicit in those instances and then arguing by analogy to the case at hand. This is because we cannot be sure that what we consider instances of unquestioned application of the statute would be what the legislature meant, nor can we be sure we are extracting from those instances the ultimate statutory purpose "implicit" in those instances and so attributable to the legislature..$^{32}$ Finally, while we can imagine possible policies that different possible ultimate purposes of the legislature here might serve, we cannot assume that the ultimate purpose of the statute coincides with any one or all of those policies. As already suggested, such policies might include preservation of quiet, or securing safety, or aesthetic considerations, or health (eliminating exhaust fumes), etc. Outcomes could well vary depending on which ultimate purpose (policy) is adopted."

Secondly, even if it were true that the argument from ordinary meaning is never alone available on the facts, it still would not follow that whatever force the argument from ordinary meaning has in such cases of joint availability must be derived solely from a concurrently applicable though unstated argument from ultimate purpose. The argument from ordinary meaning qualifies on its own as an autonomous type of argument itself having genuine justificatory force. As we have seen, when appropriately in play it serves basic interpretive values such as the implementation of legislative will, accountability of the legislature to the electorate, the generation of definite and certain reasons for action from the very inception of the law, the protection of justified reliance on the language of the law, restriction of the power of wilful judges and wilful administrators, and more. Observe that the argument from ultimate purpose does not serve some of these values at all and serves others only limitedly.

This is not to say that the argument from ordinary meaning is always wholly autonomous. It may need "help" from an available argument from ultimate purpose as where a vague word ("vehicle") confronts a borderline case ("rollerskates"), or as where a facially ambiguous statute can, when ultimate purpose is taken into account, be rendered more determinate. Ultimate purpose, then, has diverse roles: (1) as a full-fledged argument which may or may not reinforce the ordinary meaning argument, and (2) as a less than full-fledged argument which may plug holes in, or otherwise strengthen, an ordinary meaning argument.

32. See Hart and Sacks, supra n 7 at pp 1151-1157 and 1413-1417. 
Thirdly, the argument from ordinary meaning and the argument from ultimate purpose may conflict. When this is so, judges in fact frequently allow the argument from ordinary meaning to prevail. In such cases of conflict, if the argument from ordinary meaning were truly parasitic on and derivative from the argument from ultimate purpose, it would always lose to that argument. But it often wins. Consider these two examples:

Example 1: Under the "no vehicles in the park" statute, assume the court refuses to exclude loud toy airplanes flown by motor through remote control by park guests, even though substantial evidence in legislative history indicates that the reduction of noise was an important ultimate purpose. Here, to exclude such toy airplanes as vehicles would strain ordinary meaning, and ordinary meaning would not be cancelled by an ultimate purpose categorically to eliminate all noise because, let us assume, the legislature chose not to implement this ultimate purpose to the fullest extent possible, given the importance of competing ultimate purposes here, such as the use of parks for recreation and play. One court has aptly remarked:

"[N]o legislation pursues its purpose at all costs. Deciding what competing values will or will not be sacrificed to the achievement of a particular objective is the very essence of legislative choice - and it frustrates rather than effectuates legislative intent to assume that whatever furthers the statute's primary objective must be the law." 33

Example 2: The court decides that the ordinary meaning of "vehicle" rules out the use of skateboards in the park, and the court so holds although there is considerable evidence in the materials of legislative history $(\mathrm{eg}, \mathrm{a}$ key report of a commission on park regulation or a key committee report) of an ultimate purpose only to rule out vehicles causing "noise and exhaust fumes", an ultimate purpose not served by ruling out skateboards. Among other things, the court here might think that the evidence of ultimate purpose is simply not sufficiently authoritative to control. (But even a full-fledged argument from ultimate purpose might not be sufficently strong to cancel an argument from ordinary meaning.)

In cases where the judge gives the argument from ordinary meaning priority, it necessarily follows that the argument from ordinary meaning does not draw any force from the defeated argument from ultimate purpose.

In the foregoing rebuttals, we have so far implicitly resisted all efforts of those who would collapse ordinary meaning argumentation into ultimate purpose argumentation. We emphasize (1) that the two are conceptually distinct; (2) the two are not rooted in identical interpretive values; (3) one may be available but the other not; and (4) the two may conflict, yet the argument from ordinary meaning triumph.

There is a temptation the other way, too, which is to regard ultimate purpose argumentation as part of ordinary meaning argumentation, at least when the ultimate purpose is present on the face of the statute and expressed

33. Rodrigues v United States 107 S Ct 1391, 1393 (1987). 
in ordinary language. This, too, should also be resisted. In such a case, ultimate purpose argumentation can be distinctly identified and given appropriate effect as an argument that either concurrently supports, or opposes, the ordinary meaning argument. If the ultimate purpose argument and the ordinary meaning argument are somehow collapsed into one, neither of these normative effects is given its due.

V

CONCLUSION

Ordinary language argumentation is multifarious and complex. We still do not fully understand it, and we believe much work remains. Even so, we hope here to have put the ordinary meaning argument on somewhat better footing. To give primacy to ordinary meaning arguments in statutory interpretation is not to prefer literal meaning of words. Nor is it to rule out the possibility of effective appeals in at least some cases to ultimate statutory purpose. But appeals to ultimate purpose, or indeed to any other type of interpretive argument, will not in general be as available or as justifiably decisive as reliance upon the resources of ordinary language. In sum, the argument from ordinary meaning is sound, autonomous and deserves primacy.

ROBERT S. SUMMERS* GEOFFREY MARSHALL $\dagger$

* McRoberts Research Professor of Law, Cornell University; Arthur L. Goodhart Visiting Professor of Legal Science, University of Cambridge, and Fellow of The Queens' College, University of Cambridge, 1991-92.

$\dagger \quad$ Fellow and Tutor in Politics, The Queen's College, University of Oxford; Andrew Dickson White Visiting Professor at Large Emeritus, Comell University. 